\title{
El Museo de Quai Branly-Jean Chirac El discurso normativo de la museología
}

\author{
The Quai Branly-Jean Chirac Museum \\ The museology normative discourse
}

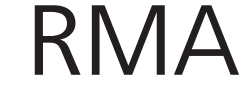

Museología

Luis Adrián Galindo

Universidad Central de Venezuela. Investigador y museólogo de la diversidad cultural y la interculturalidad. E-mail: luisgalindo@yahoo.com

\section{Resumen}

Hoy como en el pasado, muchos museos etnográficos o de las culturas en el mundo, continúan escenificando un orden social establecido hegemónicamente. En ellos el discurso normativo de la museología eurocentrista logra imponerse a partir de la concepción de su estructura narrativa, la selección de sus objetos de exhibición y la puesta en escena, fortaleciendo asi el pensamiento neoliberal que promulga la diversidad cultural como la sumatoria de culturas que comparten un mismo territorio, sin contradicciones, sin asimetrías, sin tensiones sociales, en una "paz social" aparente y en una relación natural con el entorno. El Museo de Quai Branly-Jean Chirac es un buen ejemplo de ello.

Palabras clave: museos; diversidad cultural; Museo de Quai Branly; museología.

\begin{abstract}
Today, as in the past, many museums of ethnography or museums of the world's cultures, continues to stage a hegemonic established social order. In them the normative discourse of the Eurocentric culture manages to impose itself from the conception of its narrative structure, the selection of its objects of exhibition and the staging, thus strengthening the neoliberal thought that promotes the cultural diversity as the summation of the cultures which share the same territory, without contradictions, without asymmetries, without social tensions, in an apparent "social peace» and in a natural relationship with the environment. The Quai Branly-Jean Chirac Museum is a good example of this.
\end{abstract}

Keywords: museums; cultural diversity; Quai Branly Museum; museology.

\section{Museología y eurocentrismo}

El discurso museológico normativo-eurocentrista se basa en taxonomías que incorporan un cierto orden necesario en la distribución de los objetos etnográficos, históricos u obras de arte dentro de las salas de exposición de los museos, expresando fundamentalmente una racionalidad científica, una jerarquización del saber y una definición del sujeto del conocimiento, desde el cual se intenta explicar realidades propias y foráneas. La imposición de un saber eurocéntrico prefigurando un tipo cultural hegemónico ha sido intensamente debatido por autores latinoamericanos como: Quijano (1992), Mignolo (1995), Lander (2000) y Dussel (2000) entre otros.

Este proceso educativo-civilizador logra a través de una segunda fase (que corresponde a la museografía), escenificar tales taxonomías en el espacio expositivo, mostrándolas como el orden "natural" del mundo o el estado natural de las cosas (arte popular/arte folklórico/ arte primitivo vs arte moderno/arte contemporáneo), que además clama por ser conocido más no transformado. Hoy como en el pasado, muchos museos etnográficos o de las culturas en el mundo, continúan escenificando un orden social establecido hegemónicamente, como una suerte de guion teatral cuyos actores (los usuarios del museo) interpretan continuamente, visita tras visita sobre el escenario museal (Galindo, 2015; 2017).

Los visitantes son conducidos a través de una secuencia de salas de exposición que van presentando un compendio de nuestros pueblos y sus culturas (los indígenas, los afrodescendientes, los mestizos, los inmigrantes...), conforme a sus particularidades históricas y sociales y su distribución geográfica en el territorio, fortaleciendo así el pensamiento neoliberal que promulga la diversidad cultural como la sumatoria de culturas que comparten un mismo territorio, sin contradicciones, sin asimetrías, sin tensiones sociales, en una "paz social" aparente y en una relación natural con el entorno. Experiencia cultural, que al ser construida desde una clase o grupo social dominante, estimula en los usuarios la mirada 
jerarquizada de sus culturas a través de geografías imaginarias, suspendiendo el tiempo de la alteridad y naturalizando las relaciones sociales.

\section{El Museo du Quai Branly y su interpretación de la diversidad cultural.}

Un ejemplo elocuente de la interpretación de la diversidad cultural desde el discurso de una museología normativa eurocentrista, es la exposición permanente del Museo del muelle Branly-Jacques Chirac en Paris. En junio de 2006 el gobierno francés inaugura el Museo du Quai Branly en Paris, fruto de la disolución del Museo Nacional de las Artes de África y Oceanía y de la incorporación de toda la colección etnográfica del Museo del Hombre. Con un total de 300 mil piezas, se crea este nuevo museo bajo la promesa de iniciar una "Institución cultural y científica de nuevo cuño, a la vez museo, centro cultural y lugar de investigación y enseñanza, el museo du Quai Branly proclama el rechazo de cualquier jerarquía, tanto de las artes como de los pueblos. El museo celebra la universalidad del genio humano a través de la deslumbrante diversidad de sus expresiones culturales" (Chirac, 2006, p.7). Todo pareciera comenzar con una ya dilatada discusión entre intelectuales, investigadores y directores de museos franceses ${ }^{1}$, sobre la ausencia casi absoluta en el Museo del Louvre de objetos culturales representativos de las sociedades de África, Oceanía, las Américas y el sureste asiático, en contraposición a la dominancia en las exposiciones del Louvre (35 mil obras en 60 mil 600 m2 de exposición actual) de obras de arte de la Europa medieval y renacentista y de las culturas antiguas y clásicas reconocidas en su historiografía hegemónica, como origen de sus culturas presentes.

Ya avanzado el siglo XX, la minusvalía de los museos de arte de las culturas colonizadas era en Paris cada vez más evidente, en contraposición a un museo del Louvre o un Centro George Pompidou que logran fortalecerse con el paso del tiempo, alimentándose del desarrollo de la museología moderna. De esta manera la pregunta de: ¿Por qué no tener un gran Louvre de las artes primitivas o artes primeras?, está en el debate de muchos intelectuales $y$ de la sociedad francesa en general de finales del siglo XX, y cuya campaña, de acuerdo con Depaigne (2006) será interesadamente liderada por un coleccionista y vendedor de objetos etnográficos, Ilamado Jacques Kerchache.

Kerchache logra entusiasmar al entonces presidente de Francia Jacques Chirac, a partir de una exposición sobre arte taino en el Grande Palais en 1992, incentivándolo a la creación de un Museo de las Artes Primeras, cuyo nombre será duramente cuestionado, hasta ser definidamente decretada su instauración como Museo Du Quai Branly en

${ }^{1} \mathrm{Al}$ respecto recomendamos la obra de Bernard Dupaigne (exdirector del Laboratorio de Etnología del Museo del Hombre de Paris): "Le scandale des arts premiers. La véritable histoire du musée du Quai Branly" Ediciones Mille et une nuits, Paris 2006.
1998. Para la formulación de este proyecto el presidente Chirac nombra en 1996 una comisión de "Arts Premiers".

Kerchache, en su objetivo de crear el Louvre de las artes primeras, enfrentó grandes oposiciones, entre ellas la herencia de la antropología francesa estructuralista, que en la figura de Claude Levi-Strauss, ya había demostrado con suficientes ejemplos etnográficos, la complejidad de las relaciones entre formas del pensamiento mágico y religioso, los modos de trabajo y la producción de la cultura material. Y en ello a los objetos rituales de tanta admiración por parte de la sociedad intelectual francesa post-colonial. Kercharche, tratando de librar el camino de escombros, lidera una ofensiva contra los etnólogos, particularmente de aquellos que trabajaban en el Laboratorio de Etnología del Museo del Hombre, que a su pensar, son incapaces de ver en los objetos etnográficos la belleza del arte, obstaculizando la entrada al Louvre de esta tipología de objetos.

"Los etnólogos no consideran en absoluto la dimensión artística de las artes de las sociedades sin escritura. África, Oceanía y América todavía están excluidas de la gran legitimidad de los museos. El arte de las sociedades ágrafas sigue siendo el punto ciego de los museos franceses. La controversia del Louvre fue rápidamente bloqueada en una relación de espalda uno a otro en la lógica del "experto" no erudito. Y entre aquellos "conservadores" muy nombrados y reconocidos que mantienen su rechazo hacia las sociedades sin escritura" (Kercharche, 1994, citado por Depaigne, 2006, p. 17) (TL).

Esta batalla entre Kercharche y los etnólogos del Laboratorio de Etnología del Museo del Hombre, entre la valoración exclusivamente estética de los objetos de la colección del Museo del Hombre y la necesaria contextualización de los objetos para una interpretación integral de las sociedades creadoras, estuvo y continua presente en el proceso de conceptualización del Museo del Quai Branly y la puesta en valor de las colecciones etnográficas en sus espacios expositivos.

El investigador Maurice Godelier, durante su participación en la creación del Museo du Quai Branly advirtió: “El objeto está muerto en sí mismo. El no da información sobre sus creadores, su historia y su cultura. Es necesario abordar los objetos desde cuatro ángulos de vista: su valor estético, su uso en la sociedad que lo produjo, su historia - aquella que llega a nosotros en nuestra cultura-, y su sociedad de origen y su historia" (Godelier citado por Dupaigne, 2006, p.142)

La obra de Depaigne (2006) reporta muy bien parte importante de este debate, pero que a nuestro parecer, desborda la discusión entre un tipo u otro de valoración del objeto, desde las fronteras interpuestas entre las disciplinas. Es suficientemente conocido por muchos, que aunque existe una amplia diversidad de paradigmas 
de análisis del arte y de los objetos de la cultura material en general, tanto en la historia del arte, como en la antropología eurocentrista, se impone un horizonte normativo que secuestra los múltiples sentidos que los objetos tienen en sus respectivos mundos culturales, y son analizados en la total suspensión de su propio tiempo por la imposición de una temporalidad única (lo contemporáneo contra lo tradicional) o en la enajenación del espacio territorial (lo cercano y lo lejano).

Consideramos que en el destino final del Museo del Quai Branly se impone el ejercicio colonial-moderno de la museología de las escisiones, que ha sabido tomar de varias disciplinas, principalmente de la historia del arte y de la antropología eurocentrista, los constructos fundamentales para vaciar de contenidos sociales y políticos, a los objetos de las sociedades colonizadas. Como muy bien lo expresa Clifford (1995) no es casual que justo cuando el expansionismo político, económico, religioso y cultural de Europa occidental ha avanzado significativamente sobre los pueblos de África, Asia y América, se crea esta "generosa categoría" global y "amplia" del arte. Como afirma este autor, es a partir del modernismo que los objetos "tribales" encuentran nicho en los discursos e instituciones del arte y de la antropología, buscando cómo "apropiarse o rescatar la alteridad, por organizar las artes no occidentales a su propia imagen, y por descubrir las capacidades humanas universales y ahistóricas" (Clifford, 1995, p. 233). Ambos discursos se oponen y se excluyen mutuamente, en su afán de interpretar y representar al Otro. "Ambos discursos presuponen un mundo primitivo con necesidad de preservación, redención y representación" (Clifford, 1995, p.240).

La Europa occidental pareciera estar ausente en el Museo du Quai Branly. En efecto ya lo había anunciado Maurice Godelier : « No encuentro una fundamentación teórica para justificar el hecho de que Europa no haya sido contemplada en el proyecto. Esta es una decisión política, una categoría política y no científica » (Godelier citado por Dupaigne, p.81) (TL). Sin embargo, podemos decir que políticamente y científicamente, Europa está ideológicamente presente en este museo en un nivel supra-objetual, ya que es precisamente parte de la intelectualidad europea la que organiza los objetos, los re-semantiza y establece un orden y jerarquías en este museo. Es la razón científica instrumental europea la que asigna lugares a los objetos en la exposición y con ellos a las culturas de origen, y en este sentido, la Europa moderna e industrial no necesita estar presente con sus objetos en este museo para fortalecer su identidad y su supremacía política. De esta forma el museo cumple con su objetivo principal de escenificar el sentido de pertenencia social de sus visitantes locales, vigorizar su arraigo cultural y prefigurar la sociedad que se desea a futuro.

\section{La puesta en escena}

El Museo du Quai Branly se conceptualiza, organiza y construye entre 1996 y 2006. Su edificación fue diseñada y equipada por Jean Nouvel a un costo de 235 millones de euros. Se trata de cuatro edificios conectados por pasarelas y pasillos, en una superficie de $25.100 \mathrm{~m} 2$, de los cuales $8.150 \mathrm{~m} 2$ están destinados para áreas para exposiciones y $6.095 \mathrm{~m} 2$ para la custodia y conservación de sus colecciones, además de centro de documentación, teatro y salas de educación e investigación. El museo está ubicado a las orillas del río Sena y a pocos metros de la torre Eiffel, lo cual resulta un lugar de gran visibilidad pública, aunado a los atractivos del edificio, como lo son un jardín-selva, la fachada cubierta de vegetación y la intervención artística de "obras aborígenes contemporáneas" integradas al proyecto arquitectónico. El acceso a las salas de exposición del museo se realiza a través de una rampa helicoidal que se desarrolla en torno a una especie de "silo" o torre de vidrios transparentes, dejando visualizar parte de la colección de instrumentos musicales. La rampa finaliza en un corredor llamado "rivière" dotado de estaciones o cubículos con pequeñas pantallas para videos documentales, alto-parlantes e interactivos sobre las culturas allí representadas. Al final de este "río", comienza a desarrollarse cuatros grandes áreas expositivas: África, Asia, Oceanía y Américas, agrupando los objetos provenientes de cada continente.

En cada una de estas áreas expositivas, destacan piezas de gran formato y atractivo visual llamadas "piezas faro" (las obras maestras) identificando cada espacio, en tanto que la mayoría de las colecciones son presentadas en vitrinas de alto diseño industrial y de amplios formatos favoreciendo la contemplación del objeto desde varios ángulos e iluminadas internamente con fibra óptica. A un lado de cada vitrina el visitante encuentra las convencionales cédulas o rótulos informativos de cada pieza. Si algún visitante desea más información debe dirigirse hasta el corredor principal (el río), y buscar entre los diversos videos e interactivos la información necesaria. El dramatismo del lugar se enfatiza a través de una iluminación artificial de muy baja intensidad, mezclada con los claros oscuros de la luz natural tamizada a través de la fachada de vidrio, gracias a una cubierta de grafismos simulando vegetación tropical. Entre la penumbra de las salas, en cada cierta distancia, aparece la "pieza faro" espectacularmente iluminada, con lo cual los organizadores esperan así transmutar el objeto ritual o de la vida cotidiana, en una obra de arte que goza de autonomía y que por su especificidad es capaz de "sobrevivir" fuera de su contexto original. Complementa las exposiciones permanentes, dos galerías suspendidas en un segundo nivel de altura, para exposiciones temporales.

Nuestra hipótesis es que aún y cuando el Museo du Quai Branly hace un esfuerzo por dotar de información 
a los 4 mil objetos etnográficos impecablemente exhibidos, no se obtiene el logro deseado. Por una parte, la concentración en un solo espacio de los recursos informativos distanciados de los objetos, pero sobre todo por la ausencia total en el discurso museológico de los sujetos creadores de estas importantes colecciones. En efecto, Jacques Kercharche, coleccionista de arte y promotor de este museo, le responde a los defensores de la contextualización de los objetos etnográficos de la siguiente manera: "¿Se imaginan ustedes a la Venus de Milo presentada entre dos maniquíes, uno tocando una flauta, y el otro vendiendo queso griego de cabra?" (Kercharche citado por Depaigne, 2006, p.54).

Los objetos aquí presentados están suspendidos en su tiempo de origen. El visitante no podrá informarse sobre lo que viven hoy las sociedades que crearon estos objetos, si son todavía colonias de Francia o Inglaterra o ya son repúblicas independientes, si tienen acceso a la televisión y al internet, si sus vidas y objetos rituales se han transformado, incluso conocer sus interpretaciones sobre estos mismos objetos, entre otros aspectos, lo cual podría ayudar al visitante a comprender que estas sociedades tienen una existencia propia, que se desenvuelve fuera del ejercicio de la descripción neocolonialista expresada en el museo. Las naciones, sus pueblos y sus creadores son de esta manera anulados como sujetos actores del conocimiento y sus creaciones presentadas como obras excepcionales, producto quizás del azar o de la ingenuidad.

Pretender que el público occidental pueda sólo a través de la contemplación lograr una interpretación problematizada sobre estos objetos, como si se tratase de obras de sus culturas más difundidas, es negar la larga y sistemática enseñanza que muchos hemos tenido de manera hegemónica sobre la historia y desarrollo del arte occidental. Educación que si posibilita, o acaso condiciona, una mirada instruida sobre los objetos del arte occidental. Aún más, no solo el público carece de amplia información sobre estas culturas no europeas, sino que en la mayoría de los casos poseen profundas visiones estereotipadas y descalificadoras sobre ellas.

Nota: Una versión preliminar y ampliada de este artículo se encuentra en mi tesis doctoral: "Eurocentrismo, interculturalidad y espacios de representación en Venezuela: los museos y la escenificación de la diversidad cultural" Universidad Central de Venezuela. FACES. Mimeo, 2009.

\section{Bibliografía}

Chirac, Jacques. 2006. Presentación en La Guía del Museo, edición del Museo du Quai Branly, Paris. France.

Clifford, James. 1995: Dilemas de la Cultura: Antropología, literatura y arte en la perspectiva posmoderna. Editorial Gedisa, Barcelona.

Dupaigne, Bernard. 2006. "Le scandale des arts premiers. La véritable histoire du musée du Quai Branly" Ediciones Mille et une nuits, Paris. France.

Dussel, Enrique. 2000: Europa, modernidad y eurocentrismo, en La Colonialidad del Saber: eurocentrismo y ciencias sociales, Edgardo Lander editor, Ediciones Faces/ UCV, Caracas.

Galindo, Luis. 2015. La escenificación de la diversidad cultural en Venezuela: El Museo Nacional de las Culturas, en Museos e identidades na América Latina, Universidad de Campinas, Sao Paulo, Brasil.

Galindo, Luis. 2018. El Guion musológico, una herramienta para la seducción, en Revista de Museología, № 71, Madrid. España.

Lander, Edgardo. 2000: La colonialidad del saber: eurocentrismo y ciencias sociales. Perspectivas latinoamericanas. UNESCO-Faces UCV, Caracas.

Mignolo, Walter.1995: The Darker side of the Renaissance. Literacy, Territoriality and Colonization, Michigan University Pres., Ann Arbor.

Quijano, Anibal, 1992. (1992): "Colonialidad y Modernidad/Racionalidad", en H. Bonilla (Comp.) Los Conquistados: 1492 y la población indígena de las Américas. FLACSO / Ediciones Libri Mundi, Quito (págs. 437-449) 